\title{
Alternative and adaptive transportation: What household factors support recovery from a drastic increase in gas price?
}

\author{
R. Bronson - W. Marshall
}

Received: 18 December 2013/Revised: 5 March 2014/Accepted: 7 April 2014/Published online: 29 April 2014

(C) Islamic Azad University (IAU) 2014

\begin{abstract}
Transportation resiliency is the ability for a transportation system to maintain or return to a previous level of service after a disruptive event. Among many methods to assess resiliency, quality and quantity of mode choice have shown to be promising. The provision of multiple transportation options helps facilitate resiliency by relieving the transportation system stress that tends to occur in many situations when only one modal option is available. This research seeks to understand how the availability of environmentally friendly transportation modal options-bicycling, walking, and transit-contribute to resiliency as caused by an abrupt doubling of gas price. By creating a multinomial logistic regression mode choice model for Denver, Colorado, we are able to measure the resiliency value of various multimodal transportation infrastructures, even if few people are using those facilities today. Results of this study suggest three paths to resiliency: higher income, proximity to downtown, and the availability of transportation options. There is a cumulative effect in these results as well; for instance, low-income, suburban areas tend to spend more of their household budget on transportation than urban, higher-income areas, thus increasing their vulnerability. Through this analysis, we also investigate how this resiliency scenario affects geographically and demographically diverse areas in Denver, as well as how investments in more environmentally sustainable modes of transportation can support more resilient communities.
\end{abstract}

\section{R. Bronson $(\square) \cdot$ W. Marshall}

Department of Civil Engineering, University of Colorado

Denver, 1200 Larimer Street, Campus Box 113, Denver, CO 80217, USA

e-mail: rachael.bronson@ucdenver.edu
Keywords Transportation resiliency · Bicycling · Walking · Transit · Multimodal transportation · Mode choice

\section{Introduction}

Transportation is critical to sustaining the economic and social vitality of communities. As these systems become more complex and integrated regionally, nationally, and internationally, their sustained safety and operation become increasingly essential to the social, economic, and environmental activities of a community (Hanson 2004). Given this intrinsic relationship, the continued operation of these transportation systems is critical to societal well-being (Freckleton et al. 2012).

One aspect of transportation that is vulnerable to both abrupt variability as well as long-term change-thus causing significant disruption to individuals, households, and the overall community - is the cost of gas. Gas prices have been increasing over the last decade and are projected to continue to increase (Lipman 2006). According to data from the US Energy Information Administration, from 2002 to 2012 gas prices have increased more than $10 \%$ annually, compounded ("Weekly U.S. All Grades All Formulations Retail Gasoline Prices (Dollars Per Gallon)" 2013). At this rate, gas prices would be more than $\$ 8.00$ / gallon in 2020. Moreover, gas prices are also subject to extreme volatility and have the potential to increase dramatically in a short time period. Such abrupt fluctuations are difficult to guard against, as the events that might cause them are unpredictable and often half a world away.

This research seeks to understand how the availability of bicycling, walking, and transit modal options contributes to resiliency as caused by an abrupt doubling of gas price. Our 
hypothesis is that the availability of these more environmentally friendly modes-even if few are using them today-contribute significantly to the resiliency of a community. Although this approach is similar to the Center for Housing Policy affordability work that measures combined housing and transportation costs (Lipman 2006), we make one important distinction: We do not assume that people pursue the same transportation mode as they did in the before case. In other words, two neighborhoods could be very similar in many respects, but if one possesses good active transportation infrastructure and/or decent transit service, that neighborhood could conceivably be less vulnerable to an abrupt gas price increase. Understanding the latent resiliency value of multimodal transportation options is where our study hopes to make a contribution.

When a crisis arises, the households that are already vulnerable because of their poor access to transportation and other vital resources will be most deprived (Fitzgerald 2012). Such vulnerable households are often those that have significant housing and transportation cost burdens. Because of the constraints and budgetary limitations to these households, they have the least access to coping resources if a crisis arises. Collectively, these households represent the weakest point in a city's capacity to mitigate such an event; in such a way, a catastrophic event not only threatens the usefulness of physical infrastructure and the built environment, but it also impacts social systems (Lipman 2006).

Policies to overcome these risks have often focused on lowering gas prices (Haas et al. 2008); however, gasoline and motor oil average only $21 \%$ of total transportation expenditures (Bureau of Labor Statistics 2013). It is not uncommon in the literature to model the economic impact of increased fuel prices via scenario planning; for example, a recent study suggested that the cost of fuel in Bangladesh could increase from $1.4 \%$ of GDP to $14.9 \%$ in such an increased fuel price scenario (Alam et al. 2013). To truly overcome the economic and societal implications of increased fuel costs, the goal must be to build resilient cities that offer a network of sustainable systems and communities (Newman et al. 2009). Broadly, resiliency is a system's capacity to manage unexpected events without catastrophic failure (Heaslip et al. 2009). A city without these resiliency measures is vulnerable to a threat that arises (Godschalk 2003).

Much of the early resiliency research was qualitative and looked at resiliency primarily through the lens of natural disasters such as hurricanes, earthquakes, or tsunamis (Foster 1995; Chang and Nojima 2001; Bruneau et al. 2003; Pelling 2003) or terrorist attacks (Battelle 2007). More recently, the concept of resiliency has become more quantitative and expanded to transportation (Berdica 2002; Cova and Conger 2004; Husdal 2004; Murray-Tuite
2006; Heaslip et al. 2010; Serulle et al. 2011). While overall resilience has been relatively well characterized as a result of the many different disciplines working on the issue, transportation resilience is less well defined. For instance, overall resilience represents the ability to perform under shock effects (shock absorption), to avoid the shock altogether (vulnerability), or the ability to recover quickly from a shock (shock counteraction) (Briguglio et al. 2005). Yet transportation resilience has to do with the ability of the transportation system to maintain a desired level of service or the time it takes to return to that level of service given a shock to the system (Heaslip et al. 2009, 2010).

The transportation research that has looked beyond resilience related to natural disasters and terrorist attacks has most often been economic (Echeverry et al. 2004; Briguglio et al. 2005; Zheng et al. 2010) and focused on issues such as gas prices (Dodson and Sipe 2006), but there has also been a strand more focused on environmental issues such as climate change (Brenkert and Malone 2005) and the social impacts of combined housing and transportation costs (Lipman 2006). Today's society has seen many low-income households relocate away from downtown in an effort to find more affordable housing (Lipman 2006). Without options beyond the automobile, these are the very same households that are likely to experience the greatest negative impact of rising gas prices.

In the book Resilient Cities: Responding to Peak Oil and Climate Change, Peter Newman et al. state that " $[t] h e$ agenda for future resilient cities is to have sustainable options available so that a city can indeed reduce its driving or VMT" (vehicle miles travelled). Newman et al. propose seven elements to achieve more resilient transportation systems that have reductions in VMT; bicycling, walking, and transit—as alternatives to driving — are central to each of these elements (2009). VMT is linked to negative effects of traffic safety, environmental health, public health, energy consumption, and other social costs of automobile user (Ewing and Cervero 2010); reducing VMT is thereby fundamental to building resiliency. However, the capacity to reduce VMT-even if a community is not doing so today-is equally important.

Decision makers need metrics and tools to assess transportation system resiliency; however, predicting and measuring transportation under disruptive events are extremely complex. Nouri and Malmasi conduct an environmental impact assessment of urban development in Tehran using an ecological vulnerability model (2004). The use of multiple metrics is another approach that has long been used with sustainability (Rassafi and Vaziri 2005) and is being used for resiliency as well. For example, Godschalk and Murray-Tuite identify ten critical components of transportation resiliency: redundancy, diversity, efficiency, autonomous components, strength, collaboration, 
adaptability, mobility, safety, and the ability to recover quickly $(2003,2006)$. Many of these elements are qualitative in nature; however, the work of Heaslip et al. attempts to quantify many of these resiliency measures by using a fuzzy inference approach (2009).

In the Heaslip et al. study, there are various attributes that support resiliency; one attribute that is central to this study is personal mode choice (2009). Transportation mode choice, for the individual and community, is the opportunity to use multiple means of transportation. The provision of multiple transportation options helps facilitate resiliency by relieving the transportation system of stress that tends to occur in many situations when only one modal option is available (Freckleton et al. 2012). Thus, creating a built environment with transportation alternatives and land uses that support them can be an important and effective strategy for building resiliency into a system (Haas et al. 2008).

For the sake of this research, modeling such transportation options represents an opportunity to better understand the impact of various resiliency scenarios. This modeling process, conducted in the summer and fall of 2013, reveals how certain communities and neighborhoods demonstrate different mode shift capabilities based upon varying environmental and demographic circumstances. This research also presents a unique understanding of the option value of environmentally friendly transportation infrastructures.

\section{Materials and methods}

The analysis in this paper focuses on the mode share for work trips in the City and County of Denver following a drastic gas price increase. Work trips were selected as they represent travel that people would likely still need to make after a gas price event. To assess this hypothetical mode shift, actual trips made in the region are analyzed under a series of gas price scenarios using a multinomial logistic regression mode choice model. These trips were extracted from the Denver Regional Council of Governments (DRCOG) Focus travel model, a regional activity model. This model was based on an in-depth travel behavior survey of 12,000 households in the Denver region, called Front Range Travel Counts (Denver Regional Council of Governments 2013).

The database output from the DRCOG Focus travel model was provided to us in the information platform Microsoft SQL Server. Several queries with specific characteristics were executed, such as 'Tour Type: Home based' and 'Tour Purpose: Work' to determine the number of total work trips from each origin traffic analysis zone (TAZ) to all work destination TAZ's. The total trips were broken down by the following four modes: automobile, pedestrian, bicycle, and transit. The trips databases were then aggregated from the TAZ to the census tract level for the home origin. For the work destination, they were aggregated from the TAZ to the neighborhood level (within the City and County of Denver) or city (in the case that a trip's work destination was located outside the City and County of Denver). There were a total of 143 home origins, which comprises the total number of census tracts in the City and County of Denver as configured in the 2010 US Census; of these origins, the top four work commute destinations were extracted. Four destinations were selected, as this number offers a sizable portion of the total trips taken in the census tract with respect to the overall distribution while still offering a viable number of total regional trips to analyze. Trips to the top four destinations were investigated for each of the 143 census tracts, for 572 in total. Data for each of the four transportation modes were collected for each of these 572 trips; this equals 2,288 different combinations.

In order to understand the bike, pedestrian, auto, and transit mode choices for each combination, the Google Maps Engine Lite tool was consulted to determine the suggested route for each mode between these origins and destinations. The geographic coordinates of each census tract centroid were determined and entered into Google Maps as the starting location. For the neighborhood destinations, the geographic coordinates of the centroid were also used. However, if the destination was outside of Denver neighborhoods and the destination was a city, Google Maps was consulted to provide the best location for the city's geographic coordinates (as the centroid of a city boundary does not often represent a city center). From these results, the top trip route option was selected for each mode, and several variables were recorded as follows:

- For the auto mode,

Travel time (minutes);

Trip length (miles); and

Whether the trip required limited access highway travel.

- For the bicycle and pedestrian modes,

Travel time (minutes);

Trip length; and

Level of traffic stress for the trip (traffic stress methodology is reviewed in the ensuing section).

- For the transit mode,

Travel time (minutes) and

Level of traffic stress for the trip.

The data collected via Google Maps are intended to provide a sense of the lowest cost route by each mode; 
actual route choice between origins and destinations may vary from Google's suggestion, but such differences should not be detrimental to our results. In the following section, the traffic stress methodology is described in greater detail including the relevant variables of interest.

\section{Traffic stress methodology}

In order to more realistically assess the alternative mode options for each trip, accounting for the fact that not everyone will bike, walk, or use transit-even in situations where those modes offer the lowest dollar cost optionswe adapted and refined the bicycle level of traffic stress approach developed by Mekuria et al. (2012). This methodology classifies streets based upon their bicycle level of traffic stress (LTS) that they exhibit to the user, and we applied our own adaptation of this methodology to the pedestrian and transit modes as well. A geographic information system (GIS) was used to assign traffic stress levels to Denver streets by the bike and walk mode, while Google Maps was used to determine transit traffic stress. By estimating the bike/pedestrian/transit LTS options, we were able to more realistically assess the ability of different population groups across Denver to shift to these modes from the driving mode. The following sections describe the methodologies used to determine these modal LTS levels.

\section{Bicycle level of traffic stress}

The bicycle LTS work of Mekuria et al. assigns four traffic stress levels to street segments and intersections based on characteristics such as operating space, speed, and intersection treatment (2012). In this methodology, we attempted to reasonably measure the stress that different types of bicyclists might experience while relying on variables that were readily available or easily measurable. The methodology we used for the analysis of Denver streets, while based on the work of Mekuria et al., focused on three traffic and street characteristics: speed, number of travel lanes, and the presence of bicycle facilities. The two data sources used in this analysis are as follows:

- A street database for the City and County of Denver available in a GIS format with attribute data for each street segment including the number of lanes, speed limit, and functional classification (local, collector, arterial);

- A street database for the City and County of Denver available in a GIS file with all of the on- and off-road bicycle facilities in Denver, including varying bicycle treatments (bike lanes, cycle tracks, etc.).

Similar to the work by Mekuria et al., four levels of stress were identified in the Denver methodology and
Table 1 Criteria for bicycle level of traffic stress (LTS), based on posted speed limit and number of travel lanes, adapted from Mekuria et al. (2012)

\begin{tabular}{llll}
\hline & $\leq 25 \mathrm{mph}$ & $=30 \mathrm{mph}$ & $\geq 35 \mathrm{mph}$ \\
\hline 2-3 Lanes & LTS 2 & LTS 3 & LTS 4 \\
4-5 Lanes & LTS 3 & LTS 4 & LTS 4 \\
6+ Lanes & LTS 4 & LTS 4 & LTS 4 \\
\hline
\end{tabular}

assigned to every street in the city. LTS 1 is acceptable for all users and includes paved off-street paths and trails only. Many adults tolerate LTS 2, while LTS 3 is unacceptable to most. Finally, LTS 4 is the highest stress and is tolerated by few individuals (Mekuria et al. 2012). The specific characteristics designating each stress level are summarized in Table 1 (with LTS 1 unlisted as it applies only to off-street paths and trails).

As an addendum to the above criteria, we assessed specific bicycle infrastructure on streets and adjusted traffic stress accordingly. For instance, if a street characterized by LTS 4 had a bike lane, this street was reassigned to LTS 3 . Also, if a lower traffic stress street intersected a higher traffic stress street, the approaching lower-stress street segment was reassigned the higher stress level. The rationale behind this is that a user will likely experience the stress of the higher LTS street when crossing that street even if the street that they were travelling on was defined by a lower-stress level.

After each street in Denver was assigned a traffic stress level, the top four work commute trips for each of the 143 Denver census tract origins were assigned a traffic stress level based upon the stress of the streets along the trip route. The LTS of the route was predicated by the highest traffic stress value assigned to any street segment along the way; thus, if a route contained largely LTS 2 streets but crossed one LTS 4 arterial, then that route was assigned the highest stress experienced by the user, or LTS 4 . These values were assessed and recorded for all 572 trips for the bike mode.

\section{Pedestrian level of traffic stress}

As with the bicycle LTS methodology, the pedestrian approach we developed similarly intends to measure the stress that pedestrians experience on a roadway by using data that are measurable and readily available. The pedestrian LTS was based upon three primary characteristics: speed, number of travel lanes, and sidewalk width. Since the bicycle LTS methodology measured these first two variables, as well as the presence of bicycle facilities [which are often installed as a countermeasure to improve pedestrian safety (Harkey and Zegeer 2004)], the pedestrian LTS methodology was built upon the bicycle LTS 
Table 2 Criteria for pedestrian level of traffic stress (LTS) based upon sidewalk width and bicycle LTS (where a LTS does not apply to sidewalk widths of less than 5 feet)

\begin{tabular}{lllll}
\hline & Bike LTS 1 & Bike LTS 2 & Bike LTS 3 & Bike LTS 4 \\
\hline $\begin{array}{l}\text { Sidewalk } \\
\geq 5 \mathrm{ft}\end{array}$ & LTS 1 & LTS 1 & LTS 1 & LTS 3 \\
$\begin{array}{l}\text { Sidewalk 4 ft } \\
\text { n/a }\end{array}$ & LTS 1 & LTS 2 & LTS 3 \\
Sidewalk 3 ft & n/a & LTS 2 & LTS 3 & LTS 4 \\
$\begin{array}{l}\text { Sidewalk } \\
\leq 2 \mathrm{ft}\end{array}$ & n/a & LTS 3 & LTS 4 & LTS 4 \\
\hline
\end{tabular}

designations. Given this approach and using the GIS data built for the bicycle LTS levels, the pedestrian analysis assigned traffic stress based upon the sidewalk width of these bicycle LTS graded streets. The data available on the sidewalk width were acquired from a citywide database in a GIS file that included all of the sidewalks in the Denver street network. Table 2 describes each pedestrian LTS designation; in the criteria, the larger the sidewalk widths contribute to lower pedestrian level of traffic stress. Since this is based upon bike LTS, sidewalk widths of less than 5 feet are not applicable to the bike LTS value of 1 since all bicycle paths (which exclusively represents bike LTS 1) in Denver are greater than this width.

The process of assigning traffic stress to the pedestrian mode option for the top four commute areas was similar to the bicycle mode. Given the trip route suggested by Google Maps, pedestrian LTS was based upon the highest stress street experienced, and this was again repeated for all 572 walking trips.

\section{Transit level of traffic stress}

Instead of focusing on street and traffic characteristics for the transit LTS methodology, this approach analyzed the transit options available for each of the four trips using Google Maps. Transit traffic stress was based upon two criteria: the number of transfers required to make the trip and whether these transit connections were available by light rail transit or commuter bus. Cognitive research conducted in the USA and Europe has shown an individual preference for light rail over bus (Scherer 2010); thus, in this methodology, light rail transit favors a lower traffic stress experience, as do fewer transit transfers. Accordingly, transit traffic stress was assigned based upon the following assignments:

- LTS 1: Light rail only;

- LTS 2: Light rail with one transfer; or bus only (no transfers);

- LTS 3: Light rail with two transfers; or any other transit combination (bus-bus or light rail-bus) with one transfer; and
- LTS 4: Light rail with three or more transfers; or any other transit combination (bus-bus or light rail-bus) with two transfers.

For each trip origin and destination, the number of transfers and transit options was assessed for the first route suggested in the Google Maps results. For the transit function, the Google Map tool defaults to the current date and time that the user is investigating. Thus, a consistent day and time were utilized: The trip was entered to arrive by 8:00 AM on the nearest Wednesday. In the analysis, if walking was determined to be more efficient than taking transit, Google Maps often recommends walking as the first option. In this case, the first instance that transit is recommended was utilized for that particular trip. Finally, if there were no transit options available for a certain trip, no LTS level was assigned. This procedure was repeated for all 572 transit trips.

\section{Statistical methodology}

The statistical relationship between mode choice and a drastic shift in gas price, with respect to the level of traffic stress of the various modes, was investigated by using a multinomial logistic regression model. The intent was to provide us with a realistic understanding of who might be able to access certain facilities. Many mode choice investigations fail to differentiate between different types of infrastructures. For instance, the bicycle pavement marking known as the sharrow (or shared-use arrow) that is present on a busy street might not be modeled any differently from a bike lane or a cycle track. In reality, there is a percentage of the population that would ride everyday on a cycle track but not in a bike lane, and there is another percentage of the population that would ride in a bike lane but not on a route marked with a sharrow. These distinctions are what we were looking to model. Accordingly, the LTS proxy variables took into account the following: the presence of different types of bicycle, pedestrian, and transit infrastructure; characteristics of the street such as number of lanes and speed of traffic; and functional classification of the street. Also considered were travel time and distance between origins and destinations, and population density and socioeconomic status (SES) variables such as household income and the percentage of minorities. Interactions among the selected variables were also tested and analyzed; in particular, interactions between the LTS and SES variables were tested. The variables used in the final models were selected in an effort to maximize model significance using the Akaike Information Criterion (AIC) value. With respect to multi-collinearity, none of the variables used in the final models were highly correlated 
with one another. For instance, travel time and distance between origins and destinations are highly correlated variables, both of which should not be used as independent variables in the same mode choice mode. Travel time turned out to be the more highly significant variable and was used in the final model.

The basic structure of a multinomial logistic regression mode choice model is derived from a basic logit model. The following generalized logit equation determines the probability of choosing a specific mode (Martin and McGuckin 1998).

$P_{i}=\frac{e^{u_{i}}}{\sum_{i=1}^{k} e^{u_{i}}}$

where $P_{i}=$ probability of somebody choosing mode $i=1$, $2, \ldots, k ; u_{i}=$ utility function describing the relative attractiveness of mode $\mathrm{i}$; and $\sum_{i=1}^{k} e^{u_{i}}=$ sum of the functions for all available mode alternatives.

The probability of choosing a particular mode depends on the above utility function relative to the utility functions for all the other mode options. In conventional four-step model transportation planning, the utility function of the logit equation typically contains variables such as invehicle travel time, out-of-vehicle travel time, and the cost associated with each mode for a particular type of trip between two specific zones. Our utility functions included travel time and costs but also took into consideration the level of traffic stress for bicycling, walking, and transit, and with respect to driving, whether or not the trip includes a limited access highway. Four mode types were modeledtransit, walking, biking, and driving - and to account for four separate categorical outcomes, a multinomial logistic regression model was used (Ben-Akiva and Morikawa 2002). A multinomial logistic regression simultaneously considers a binary logit model for every possible combination of outcomes; in this study, the four different outcomes are equivalent to six binary logit models (Long 1997). One assumption of this model is that the probabilities related to the mode choices sum to 1 :

$P($ transit $)+P($ walking $)+P($ biking $)+P($ driving $)=1$.

For such a probability-based model, the multinomial logistic regression equation is as follows:

$\begin{array}{ll}P\left(y_{i}=1 \mid x_{i}\right)=\frac{1}{1+\sum_{j=2}^{J} e^{\left(x_{i} \beta_{j}\right)}} & \text { for } m=1 \\ P\left(y_{i}=m \mid x_{i}\right)=\frac{x_{i} \beta_{m}}{1+\sum_{j=2}^{J} e^{\left(x_{i} \beta_{j}\right)}} & \text { for } m>1\end{array}$

where $y=$ dependent variable, $j=$ number of categorical outcomes for four mode choices, $P(y=m \mid x)=$ probability of choosing mode $\mathrm{m}$ given $x, x_{i}=$ independent predictor variable, and $\beta=$ estimated coefficient representing the effects of the independent variable.

The probability of the four modes (transit, walking, biking, and driving) was calculated for the top four work trip destinations for each Denver census tract origin using the multinomial logistic regression model for a baseline gasoline price of $\$ 2.70$ and a doubling of that price to $\$ 5.40$ per gallon. The base gas price was chosen because it was the prevailing gas price estimate for Denver region when the Front Range Travel Survey (a 12,000 household travel survey for the region from which our data were gathered) was being administered (Denver Regional Council of Governments 2013). This gas price was used to determine the average annual cost of gas for each 572 commute trips using an average vehicle efficiency of 20.2 miles per gallon, which was the national average during the same time period (Environmental Protection Agency Office of Transportation and Air Quality 2007). We then calculated the average annual percent of the median household income spent on gas for each census tract on commute trips, a value that could be doubled in the model to reflect the resiliency scenario. This informed the cost of driving for these work commute trips.

Table 3 provides the descriptive statistics of all of the data that were put into the model. This includes the following for each variable: the minimum and maximum values, the mean, standard deviation (SD), and the number of observations. The values in Table 3 represent the data for each origin via all four modal options. For instance, the average number of minutes walking to work value is based on all origins to all destinations, which does not reflect actual behavior but is needed for the mode choice model. Table 4 shows the results of the mode choice model.

Results of the mode shares for a given home census tract were weighted based upon the relative number of trips. For example, if the top 4 destinations for a home zone have 100 people total and 60 of them were going to destination A with $80 \%$ auto mode share, 20 to B with $60 \%$ auto mode share, 15 to $\mathrm{C}$ with $90 \%$ auto mode share, and 5 to D with $40 \%$ auto mode share, the home census tract automobile mode share would be $75.5 \%$, as follows:

$0.755=\frac{0.8(60)+0.6(20)+0.9(15)+0.4(5)}{100}$.

To determine mode shift at the census tract level after a twofold increase in gas price, each trip taken in each Denver census tract was averaged and normalized based upon the actual number of trips taken for each origin and destination. Data used for this analysis were from the 2010 American Community Survey (ACS), administered by the US Census (Social Explorer 2013). 
Table 3 Descriptive statistics of the data used in the multinomial logistic regression mode choice model

\begin{tabular}{|c|c|c|c|c|c|}
\hline Variable & Obs & Mean & SD & Min & Max \\
\hline \multicolumn{6}{|l|}{ Misc. } \\
\hline Population of origin census tract & 2,288 & $4,129.42$ & $1,567.84$ & 314.00 & $9,462.00$ \\
\hline Population density of origin census tract & 2,288 & $7,032.95$ & $3,938.61$ & 28.51 & $24,770.81$ \\
\hline Percent minority in origin census tract & 2,288 & 25.20 & 17.12 & 0 & 79.91 \\
\hline Median $\mathrm{HH}$ income of origin census tract & 2,288 & $52,354.48$ & $24,550.32$ & $9,571.00$ & $153,571.00$ \\
\hline \multicolumn{6}{|l|}{ Automobile } \\
\hline \# of driving miles to work (avg.) & 2,288 & 6.47 & 4.74 & 0 & 27.40 \\
\hline \# of minutes driving to work (avg.) & 2,288 & 13.80 & 6.61 & 0 & 40 \\
\hline Whether car trip to work includes hwy driving (avg. of 0,1 variable) & 2,288 & 0.46 & 0.50 & 0 & 1 \\
\hline Proportion of income spent on annual driving to work (avg.) & 2,288 & 0.01 & 0.01 & 0.00 & 0.11 \\
\hline \multicolumn{6}{|l|}{ Transit } \\
\hline \# of minutes for transit trip to work (avg.) & 2,224 & 44.60 & 23.73 & 0 & 123 \\
\hline \# of transfers for transit trip to work (avg.) & 2,224 & 0.55 & 0.64 & 0 & 3 \\
\hline Whether transit trip to work includes light rail (avg. of 0,1 variable) & 2,224 & 0.14 & 0.35 & 0 & 1 \\
\hline Transit LTS score for trip to work (avg.) & 2,224 & 2.48 & 0.72 & 0 & 4 \\
\hline \multicolumn{6}{|l|}{ Walk } \\
\hline \# of walking miles to work (avg.) & 2,288 & 5.86 & 13.01 & 0 & 304.00 \\
\hline \# of minutes walking to work (avg.) & 2,288 & 106.00 & 71.62 & 0 & 469 \\
\hline Walking LTS score for trip to work (avg.) & 2,288 & 3.60 & 0.66 & 0 & 4 \\
\hline \multicolumn{6}{|l|}{ Bike } \\
\hline \# of biking miles to work (avg.) & 2,288 & 6.22 & 4.28 & 0 & 26.80 \\
\hline \# of minutes biking to work (avg.) & 2,288 & 35.35 & 23.30 & 0 & 138 \\
\hline Biking LTS score for trip to work (avg.) & 2,288 & 3.93 & 0.44 & 0 & 4 \\
\hline
\end{tabular}

\section{Results and discussion}

Census tract analysis

In reporting the results, we first explore expected trends at the census tract level for the entire City and County of Denver, and then we explore trends and contributing factors further by investigating expected changes at six specific census tracts. We compare mode shifts at the census tract level in Denver in a scenario where the gas price doubles, from a base price of $\$ 2.70$ per gallon (the baseline scenario) to a twofold increase of $\$ 5.40$ (the resiliency scenario).

For each 143 Denver census tracts, after the resiliency scenario, car mode share decreased by varying amounts, while bicycle, walking, and transit mode shares increased. These data are best depicted spatially in Fig. 1, where the changes in car mode shares in each census tract are shown. Figure 1 is compared side-by-side to Fig. 2, where the change in driving mode share is displayed with income held constant. Figures 1 and 2 also illustrate the major street network, bicycle paths, and light rail facilities in Denver.

Those census tracts that have the highest change in driving mode share, displayed in Fig. 1 as the darker shaded color, have a greater shift away from driving to transit, biking, and walking. Many of these census tracts appear to be located away from the Central Business District (CBD), particularly scattered throughout the southwestern areas of Denver. On the other hand, those census tracts with the lowest shift in driving mode share appear to be clustered around the CBD and in the northeast areas of Denver. These more urban census tracts already have a lower driving mode share; thus, the driving mode shift after the resiliency scenario is less acute. Other socioeconomic or demographic factors may also affect the shift as it occurs in different geographic census tracts.

In order to understand what other factors may be impacting these trends, we held income constant for all Denver census tracts and displayed the results in Fig. 2. The Metro Denver Economic Development Corporation reports that for 2011, the median household income in Denver was \$59,230 (Metro Denver Economic Development Corporation 2013). In Fig. 2, the darker colors again indicate the higher shift away from driving mode share. There is a significant group of these census tracts with a higher shift away from the driving mode share located south of the CBD. These census tracts are not adjacent to the $\mathrm{CBD}$, but they are surrounded by high ease-of-use transit and bicycling facilities: light rail transit and multiple 
Table 4 Results of the mode choice model

\begin{tabular}{|c|c|c|c|}
\hline Variable & Transit & Walking & Biking \\
\hline Intercept & $0.6197 * * *$ & $1.9941 * * *$ & $1.1106^{* * *}$ \\
\hline \multicolumn{4}{|l|}{ Miscellaneous } \\
\hline Population of origin census tract & 0.00008 & 0.00021 & $0.00014 * * *$ \\
\hline Population density of origin census tract & $0.000071 * * *$ & $0.000095 * * *$ & $0.000055^{* * *}$ \\
\hline Percent minority in origin census tract & $0.00799 * * *$ & $0.0155^{* * *}$ & $0.0032 *$ \\
\hline Median $\mathrm{HH}$ income of origin census tract & $0.00000294 * *$ & $0.000003639 * *$ & $0.000007592 * * *$ \\
\hline \multicolumn{4}{|l|}{ Driving } \\
\hline \# of driving miles to work (avg.) & $0.1477 * * *$ & $0.7477 * * *$ & $0.1907 * * *$ \\
\hline Proportion of income spent on annual driving to work (avg.) & $45.4014 * * *$ & $66.357 * * *$ & $50.6937 * * *$ \\
\hline \multicolumn{4}{|l|}{ Transit } \\
\hline Transit LTS score for trip to work (avg.) & $0.4131 * * *$ & 0.0249 & $0.3663^{* * *}$ \\
\hline Whether transit trip to work includes light rail & $0.7098 * * *$ & $0.4461 * * *$ & $0.2331 * *$ \\
\hline \multicolumn{4}{|l|}{ Walking } \\
\hline Walking LTS score for trip to work (avg.) & $0.313 * * *$ & $0.3473 * * *$ & $0.2145^{* * *}$ \\
\hline \multicolumn{4}{|l|}{ Model fit } \\
\hline Observations & 2,224 & & \\
\hline
\end{tabular}

$* p<.10, * * p<.05, \quad * * * \mathrm{p}<.01$

Fig. 1 Change in car mode share by census tract in City and County of Denver after the resiliency scenario

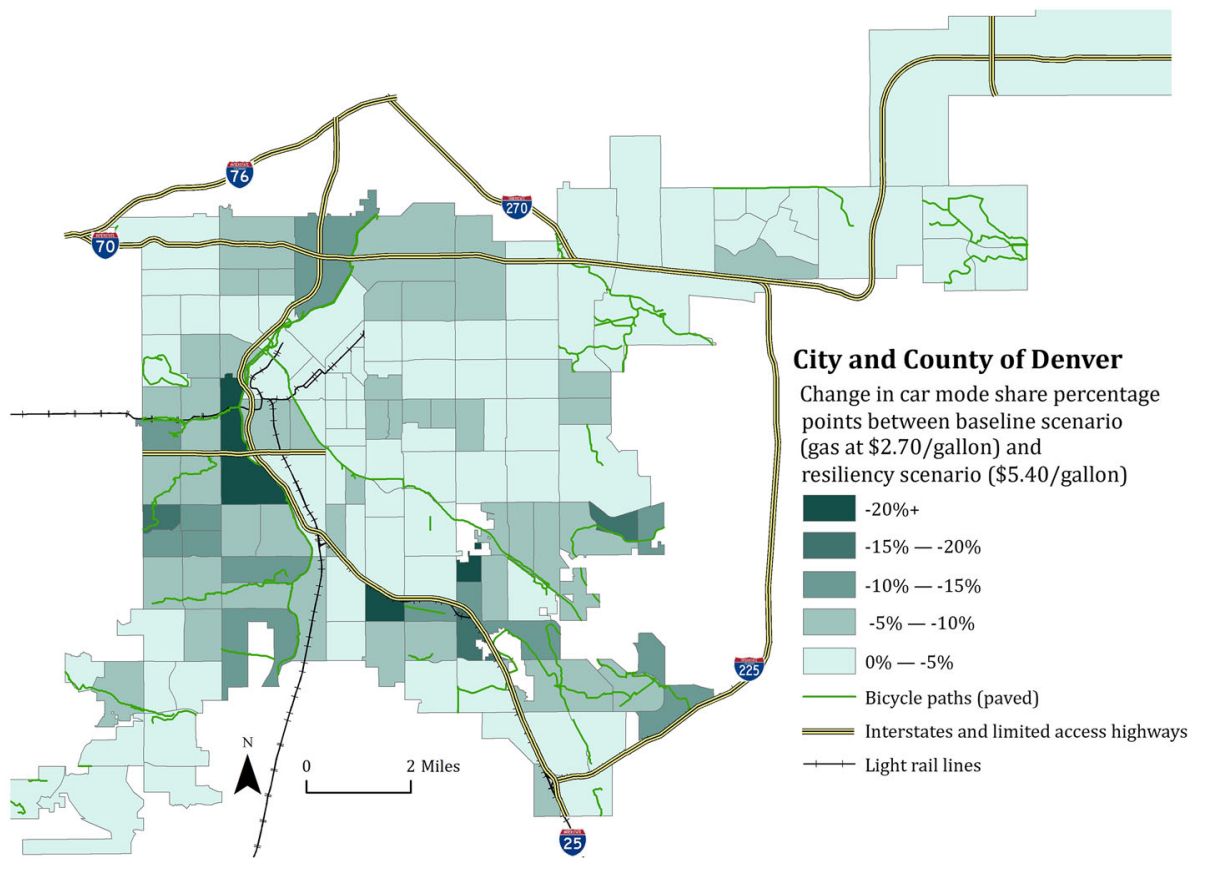

bicycle paths. Thus, it appears that there are factors in addition to income that may be impacting mode share, and further analysis is merited to better understand what these elements may be.

\section{Census tract study areas}

\section{Study area characteristics}

Since it seems that geographic and demographic factors impact transportation choices after the change from the baseline to the resiliency scenario, we take a closer look at mode shift trends in six Denver census tracts. In selecting these census tracts, our variables of interest are proximity to downtown and income. We selected three census tracts that are situated closer to the city center and three that are in more suburban locations. We also chose census tracts that have low, middle, and high median household incomes, selecting two in each income range (based on 2010 ACS household income values) (Social Explorer 2013). To facilitate the comparison, we also selected census tracts that share the following two top work 
Fig. 2 Change in car mode share after the resiliency scenario where income is held constant at $\$ 59,230$

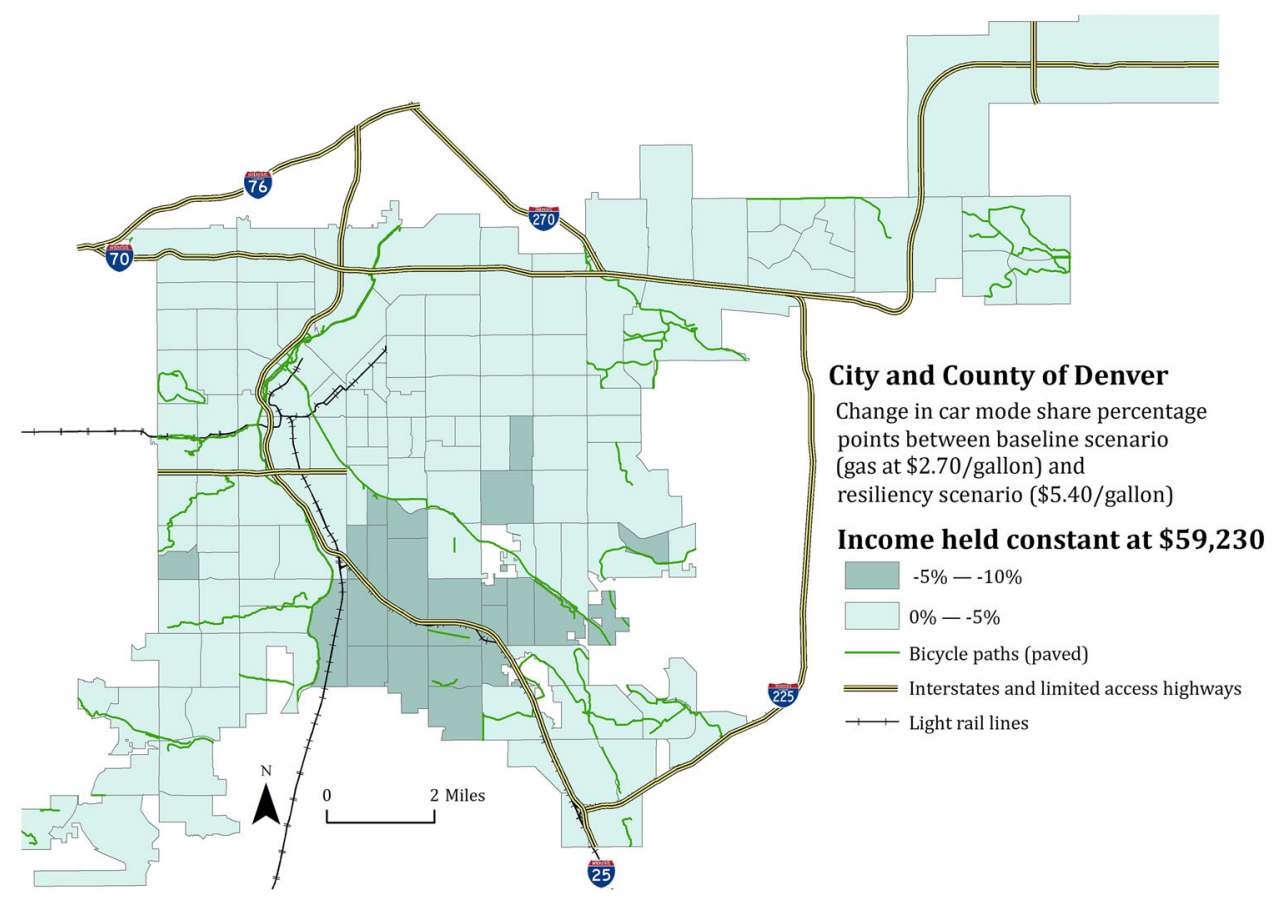

destinations: Denver CBD and the City of Aurora (located to the east of Denver city limits).

The six census tract origins that were selected for this analysis will be referred to by the neighborhood contained within the census tract, not by the census tract number. Globeville, an urban census tract with lower household income, is located just north of the CBD. College View/S Platte is a lower income, suburban census tract that is located in the southern part of the Denver city/county limits. City Park West is a middle-income census tract that is located just east of the CBD. Sunnyside is also a middleincome census tract, but it is located in the northwestern portion of the Denver limits. Finally, Country Club is a higher-income census tract that is located directly southeast of the CBD, while Stapleton is high-income census tract that is located near the northeast corner of Denver city/ county limits (Table 5 describes these census tract selections in further detail).

Work trips from these six census tracts to two destinations (Aurora and the CBD) were analyzed. Aurora and the CBD are two of the top four of work commute destinations for each origin census tract. Additionally, the CBD and Aurora represent an urban and suburban destination, respectively, which is relevant to our analysis of urban and suburban trip origins.

In the analysis of these census tracts, three elements have a significant impact on mode shift in our six census tracts and are further explored: proximity to downtown, income, and availability of multimodal transportation infrastructure.

\section{Proximity to downtown}

Results from the mode choice model reveal that for the six Denver census tract study areas, the driving mode share is consistently higher for suburban census tracts origins as compared to their urban counterparts. Trips from Stapleton, Sunnyside, and College View/S Platte have higher driving mode share than trips from Country Club, City Park West, and Globeville. Figure 3 illustrates these trends for work trips from the six census tract study areas to the CBD. This trend is particularly acute for the higher-income census tracts: Stapleton and Country Club. A factor influencing this is that Stapleton is significantly further from the CBD than Country Club (12 miles vs. 2.9). Globeville and College View/S Platte-low-income census tracts-also are quite different in their distance to the CBD (3.4 and 17.8 miles, respectively), but do not display the driving mode share difference that the high-income study areas do.

Another interesting trend related to the driving mode share is that all trips to the CBD, regardless of the origin, have lower driving mode share than those same trips to Aurora. So, in addition to driving mode share being impacted by proximity to downtown of the trip origin, it is also impacted by the proximity to downtown of a household's destination. Figure 4 displays this trend.

When comparing the trends in Figs. 3 and 4, we see that the car mode share from Stapleton to the CBD (95\%) and to Aurora $(97 \%)$ for the resiliency scenario remains fairly unchanged. In these cases, nearly all of the households are already opting to drive for both their trip to Aurora and the 
Fig. 3 Car mode share to the $\mathrm{CBD}$ in the baseline and resiliency scenario for the six census tract study areas

\section{Car Mode Share to the CBD}

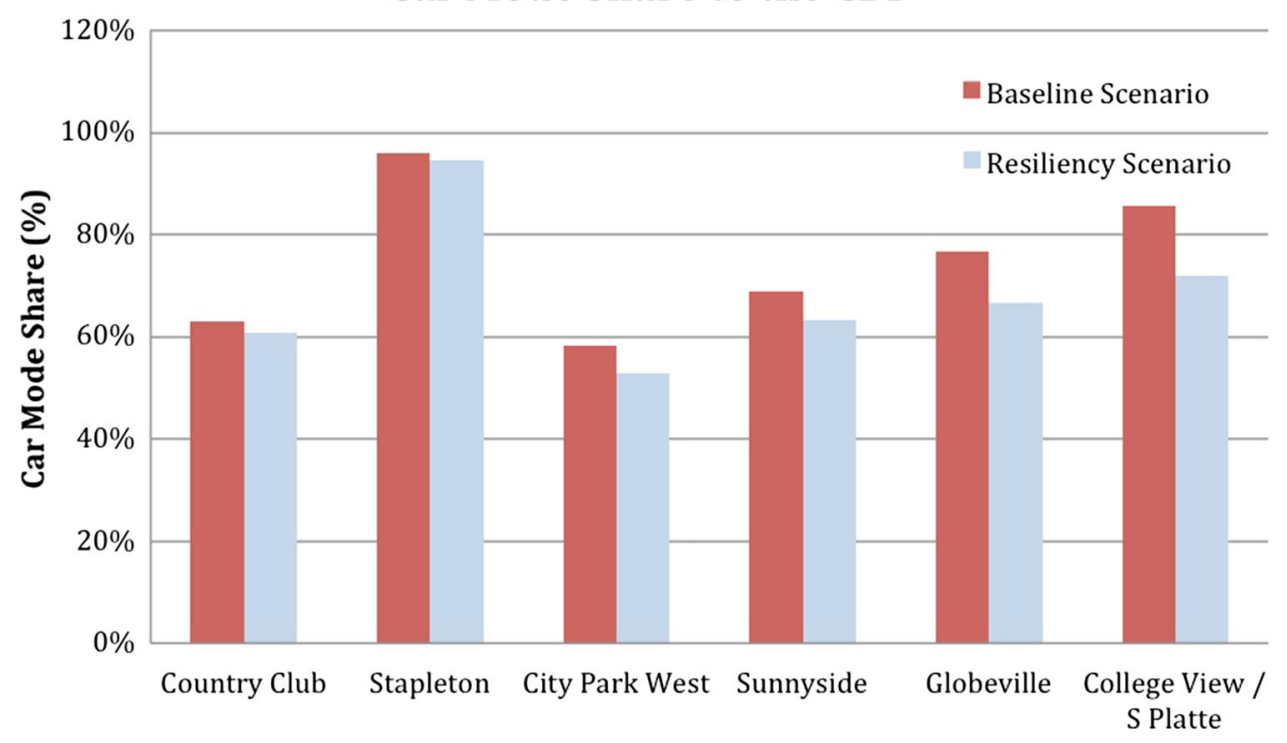

CBD. However, most of the other study areas show a significant increase in car mode share for the trips to Aurora when compared to the CBD for the resiliency scenario. Because of this overall higher mode share across all study areas, the difference in car mode share between urban and suburban census tracts and Aurora is less dramatic than it was in Fig. 3.

\section{Income}

One important impact of the trip distance differences for those people living in the urban and suburban origins, particularly as it relates to resiliency, is the fact that it directly impacts their household budgets in terms of gas expenditures. Those households in the suburban origins that have a farther distance to travel for work trips are spending more money on gas than their urban counterparts. This discrepancy impacts low-income households more than high-income areas in terms of the percent of income spent on gas. With high household income, these census tracts have more capacity to withstand increases in gas price than those areas with more constrained financial resources. For this reason, we would expect to see less of a change in driving mode shift for high-income areas when compared to lower-income areas after the resiliency scenario.

This trend is indeed apparent in Fig. 4 for trips to Aurora. For the middle- and higher-income households with the resiliency scenario, car mode share generally remains high. With more income available to these high-income households, they can better cope with higher costs of driving and do not necessarily have to change their travel behavior to mitigate the impact to their budget. On the other hand, for the low-income households (Globeville and College View/S Platte), car mode share falls more substantially in the resiliency scenario. The same trend occurs for trips to the CBD as displayed in Fig. 3, although it is less acute. In Fig. 3, the shift away from driving after the resiliency scenario is greater for the lower-income census tracts than for the middle- and higher-income households.

To further understand this trend, we determined the percent income spent on gas for each trip. As discussed in the 'Materials and Methods' section, we were able to calculate this value based upon the length of the trip in miles, and assuming an average vehicle efficiency of 20.2 miles per gallon (Environmental Protection Agency Office of Transportation and Air Quality 2007). Results revealed that higher-income households (Stapleton and Country Club) spent the least percentage of their household budget on gas for trips to Aurora than any other census tracts being reviewed-even with the resiliency scenario (see Fig. 5). For trips to the CBD in the resiliency scenario, lowerincome households spent more of their income on gas than other areas. When compared to percent of income spent on gas for trips to Aurora, trips to the CBD have less impact on household income-which again is due to the distance of these trips and amount of gas used. Finally, suburban trips have a higher percent income spent on gas than their urban counterparts, except for the Stapleton to Aurora trip (which relates to the fact that this trip is shorter in distance than Stapleton to the CBD).

In order to understand how other factors may be influencing mode share, we again hold income constant, this time specifically for the six census tract study areas. In doing so, we expect to better understand the extent to which proximity to downtown and other variables may impact mode share. With a median household income 
Fig. 4 Car mode share to Aurora in the baseline and resiliency scenarios for the six census tract study areas

\section{Car Mode Share to Aurora}

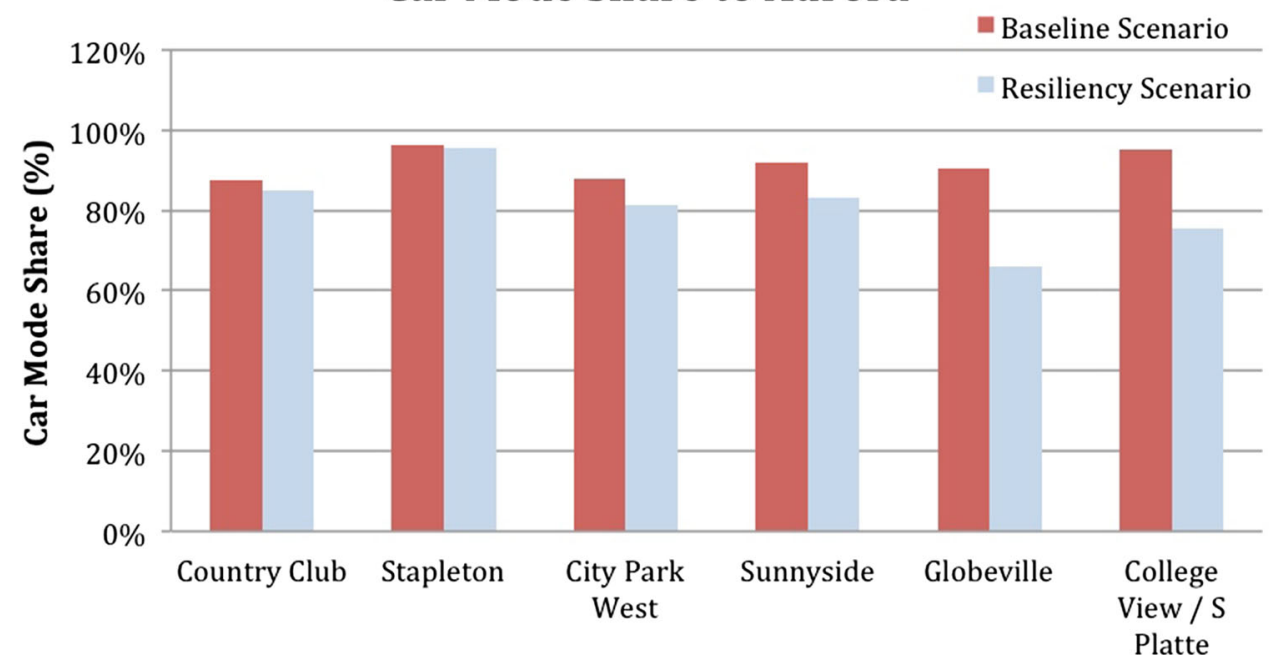

Fig. 5 Percent of income spent on gas for households traveling to Aurora at both the baseline and resiliency scenarios

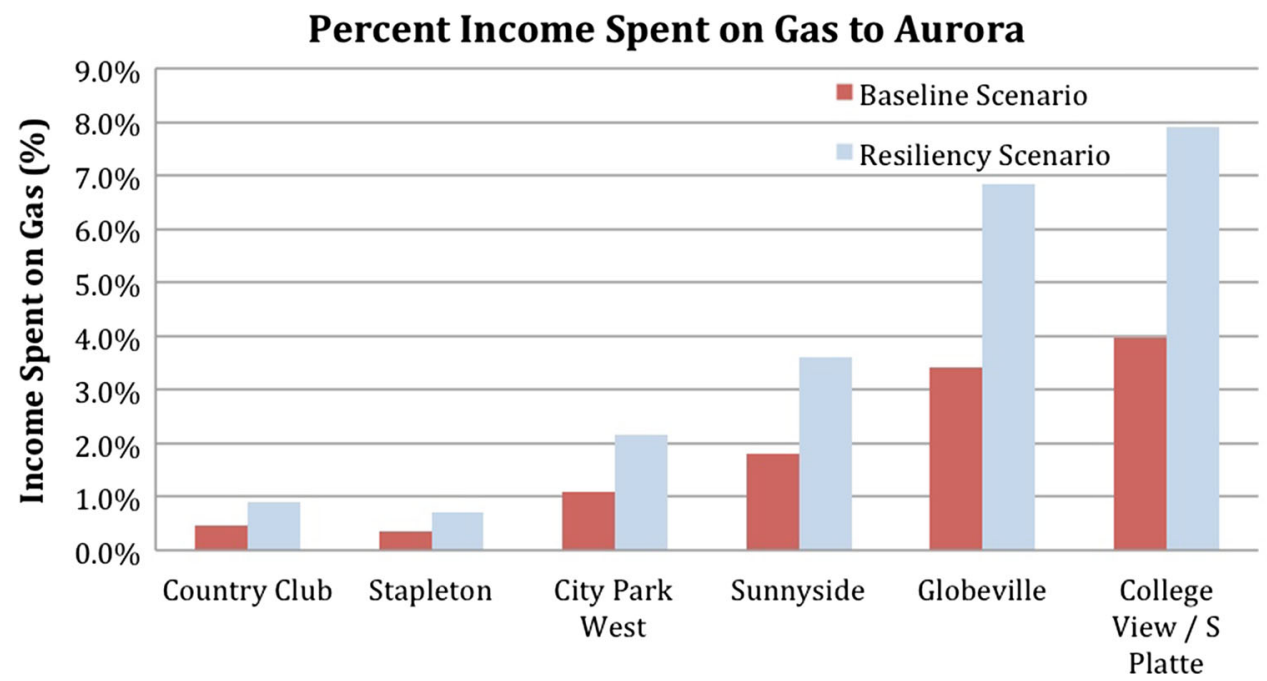

again adjusted to $\$ 59,230$ for the six census tract study areas, car mode share in certain areas experiences some interesting changes, as depicted in Table 6 (Metro Denver Economic Development Corporation 2013). Table 6 lists the changes in car mode share for the baseline and resiliency scenarios under their normal household income as well as the values before and after the resiliency scenario under the adjusted income.

In Table 6, for both the actual and adjusted incomes, the baseline car mode shares are consistently higher than the resiliency scenario car mode shares. Country Club and Stapleton (which normally exhibit median household income above $\$ 130,000$ ) experience a greater shift in driving mode share under this adjusted income level with the resiliency scenario. With less income at their disposal, the formerly higher-income areas have a greater shift away from driving when their income is adjusted to $\$ 59,230$. On the other hand, the lower-income households in Globeville and College View/S Platte have less of a shift away from the driving mode share when their income is adjusted. In other words, these formerly lower-income areas maintain a higher driving mode share during the resiliency scenario when their income is increased to the adjusted value of $\$ 59,230$; with more income, these areas would be less reliant on alternative modes of transportation in coping with the resiliency scenario.

Another trend under the adjusted incomes is that two of the more urban census tracts, Country Club and Globeville, have a higher shift away from the driving mode share after the resiliency scenario than their suburban counterparts. In these areas, more people are opting to take alternative forms of transportation with the resiliency scenario. However, City Park West, the third urban census tract, does not display this trend, which suggests that another demographic or environmental factor may be involved in favoring Sunnyside (suburban, middle-income census tract) 
Table 5 Household and housing characteristics of each origin census tract in Denver (Social Explorer 2013)

\begin{tabular}{|c|c|c|c|c|c|c|}
\hline & \multicolumn{2}{|c|}{ Low income } & \multicolumn{2}{|l|}{ Middle income } & \multicolumn{2}{|l|}{ High income } \\
\hline & Globeville & College/ S Platte & City Park West & Sunnyside & Country Club & Stapleton \\
\hline Driving distance to $\mathrm{CBD}$ (miles) & 3.4-urban & 17.8 & 2.9-urban & 3.7 & 2.9-urban & 12 \\
\hline Median HH income & $\$ 24,190$ & $\$ 30,076$ & $\$ 51,371$ & $\$ 51,163$ & $\$ 130,321$ & $\$ 133,393$ \\
\hline No. persons per $\mathrm{HH}$ & 3.1 & 3 & 2.2 & 2.5 & 2.5 & 2.8 \\
\hline Home values & $\$ 164,200$ & $\$ 170,300$ & $\$ 325,100$ & $\$ 218,500$ & $\$ 723,100$ & $\$ 458,600$ \\
\hline Monthly rent & $\$ 833$ & $\$ 710$ & $\$ 667$ & $\$ 714$ & $\$ 964$ & $\$ 1682$ \\
\hline Pop density & 1544 & 4258 & 7302 & 5705 & 4761 & 1686 \\
\hline$\%$ Non-white & $30 \%$ & $37 \%$ & $30 \%$ & $20 \%$ & $16 \%$ & $17 \%$ \\
\hline \% Hispanic or Latino & $80 \%$ & $64 \%$ & $10 \%$ & $62 \%$ & $4 \%$ & $16 \%$ \\
\hline
\end{tabular}

Table 6 Car mode share normalized for six census tract study areas under a normal and an adjusted income of $\$ 59,230$

\begin{tabular}{|c|c|c|c|c|c|c|}
\hline & \multicolumn{3}{|c|}{$\begin{array}{l}\text { Car mode share under actual } 2012 \text { median } \\
\text { household income }\end{array}$} & \multicolumn{3}{|c|}{ Car mode share with income held constant at $\$ 59,230$} \\
\hline & $\begin{array}{l}\text { Baseline } \\
\text { scenario }(\%)\end{array}$ & $\begin{array}{l}\text { Resiliency } \\
\text { scenario }(\%)\end{array}$ & $\begin{array}{l}\text { Change in car } \\
\text { mode share }(\%)\end{array}$ & $\begin{array}{l}\text { Car mode share, } \\
\text { adjusted income }(\%)\end{array}$ & $\begin{array}{l}\text { Resiliency car mode share, } \\
\text { adjusted income }(\%)\end{array}$ & $\begin{array}{l}\text { Change in mode } \\
\text { share }(\%)\end{array}$ \\
\hline Country Club & 73.5 & 71.2 & -2.3 & 75.8 & 70.6 & -5.2 \\
\hline Stapleton & 94.6 & 93.8 & -0.8 & 95.1 & 93.1 & -2.0 \\
\hline $\begin{array}{l}\text { City Park } \\
\text { West }\end{array}$ & 58.0 & 53.3 & -4.7 & 57.9 & 54.0 & -3.9 \\
\hline Sunnyside & 81.9 & 75.8 & -6.1 & 82.1 & 77.2 & -4.9 \\
\hline Globeville & 76.7 & 64.6 & -12.1 & 79.5 & 76.0 & -3.5 \\
\hline $\begin{array}{l}\text { College } \\
\text { View/S } \\
\text { Platte }\end{array}$ & 87.6 & 76.8 & -10.8 & 89.6 & 86.2 & -3.4 \\
\hline
\end{tabular}

to have a greater shift driving mode shift. Finally, the areas with the highest driving mode share under the adjusted income are Stapleton and College View/S Platte, which are farther from downtown.

\section{Alternative transportation infrastructure}

An important influence to mode share for certain census tracts is the availability of low-stress, environmentally friendly transportation options. With more transportation modes available to urban origins, individuals and households-particularly those with budget constraints-may choose transportation options other than driving for their work travel needs. Thus, in addition to proximity to downtown, another variable that impacts mode shift is availability of active transportation options-and the level of traffic stress of those options.

In the mode choice model, bicycle LTS was removed since it was highly correlated with walk LTS. Thus, we analyzed walk LTS to understand how bike LTS may also correlate with mode choice. For the walk mode, only three trips to the CBD from census tract origins are of the lowest traffic stress, LTS 3: Sunnyside, City Park West, and Country Club. Consequently, these trips have some of the highest walk mode share, respectively: 4, 22, and $10 \%$ (reported for the baseline scenario). It is interesting to note that Country Club and City Park West are urban areas (while Sunnyside is not); yet, they all have the highest walk mode shares of all six study areas. This suggests that the low traffic stress walking experience for those traveling from Sunnyside to CBD is correlated with improving the walk mode share for this suburban area. During the resiliency scenario, these walk mode shares for Sunnyside, City Park West, and Country Club increase to 6, 24, and $11 \%$ (respectively). Because these trips are less stressful, traveling along streets with lower speed, wider sidewalks, and fewer lanes, individuals are more likely to shift to the walk mode for their work transportation needs.

Another area of analysis indicating that factors related to the transportation environment impacted the trips from Country Club, City Park West, and Sunnyside were the results in Table 6 . We will recall that in Table 6 , when income is held constant, the areas with the largest shifts away from driving mode share include these census tracts. 
Given that only two of the census tracts (Country Club and City Park West) are proximate to downtown suggest that other factors allow for the higher shift away from driving mode share for Sunnyside, which is not as near to downtown. After this analysis of alternate modes of transportation, it is clear that the level of traffic stress is important in impacting that mode shift.

When compared to trips to the CBD, walking trips to Aurora are more stressful. No trips to Aurora by foot are less than LTS 4. This suggests the extent to which this suburban destination does not support the pedestrian mode of transportation and how the driving mode share to Aurora from households throughout Denver remain as high as it is (refer to Fig. 4).

Transit LTS is measured by the number of transfers and whether the trip includes light rail transit or commuter bus. Of all of the trips in the study areas, the only trip of LTS 4 is from Stapleton to Aurora. This trip has the lowest transit mode share of $3.2 \%$ at the baseline scenario. Trips that are of transit LTS 2 range in mode share from 3.7 to $21.0 \%$, with the lower range value being impacted by a higher trip length and duration.

Sunnyside, the more suburban of the middle-income census tracts, has a higher transit mode share to Aurora than that same trip from City Park West, its urban counterpart. This is likely because the transit level of traffic stress from Aurora to Sunnyside is only a value of two, while to City Park West it is LTS 3. This indicates that the trip from City Park West is more stressful than the trip from Sunnyside with respect to the number of transfers (since light rail transit does not serve this trip). This further demonstrates how the transit experience, measured in traffic stress, can influence mode share even when there may be disparities in trip length and distance.

\section{Conclusion}

In measuring mode shift before and after a drastic increase in gas price, this study sought to understand how certain areas in Denver, $\mathrm{CO}$, with various environmental and demographic characteristics, are better equipped to return to a normal level of service than other areas. In terms of this mode shift, we focused not on how individuals are behaving today, but on what they have the ability to do in a disruptive gas price event based upon these environmental and demographic characteristics. Results of the model revealed that certain neighborhoods and individuals are better suited to withstand a disruptive gas price event. Three attributes appeared to be most relevant in these trends: household proximity to downtown, median household income, and the availability of multimodal transportation options. All told, the closer to downtown, the higher the household income, and the better the accessibility to environmentally friendly and lower stress modes of transportation, the better able certain areas in Denver are to react to the disruptive event.

Several limitations should be considered in this research. For the traffic stress analysis, lack of data about average annual daily traffic or actual speeds along roads limited the analysis of stress along certain roads. Additionally, the sidewalk data provided by the City and County of Denver were ten-year old and did not offer an up-to-date understanding of sidewalk presence and condition. In the assignment of traffic stress to trips, extrapolating from the TAZ to the census tract may have diminished accuracy of the trips, further exacerbated by the random selection of census tract or neighborhood centroid as the start and end of each trip. In the development of the mode choice model, it was assumed that the total of car, transit, walk, and bicycle modes would equal $100 \%$, which is not necessarily accurate as some people telecommute and work from home.

Despite these limitations and assumptions, the contribution of this work to understanding travel behavior under a resiliency scenario is critical. This research offers an important approach to valuing transportation options and to understanding the latent worth of environmentally sustainable infrastructure, even if it is not heavily used today. Future direction of this research is promising. By utilizing a mode choice model to understand where reductions in traffic stress offer significant shifts to these alternative modes, we can better understand what infrastructure improvements to the current bicycling, walking, and transit network will facilitate additional resiliency. These improvements can be readily determined by analyzing the traffic stress of streets and trips, thereby ensuring that a lower-stress environment exists through enhancements such as buffered bicycle lanes or better bus service. Such future applications of this research can be utilized to connect and improve bicycle, pedestrian, and transit networks, further strengthening these environmentally friendly transportation modes so that they may support the communities that they serve.

Our work reveals that to build more resiliency into communities and neighborhoods, policy makers and leaders need to improve accessibility to low-stress alternatives to driving, particularly in areas that possess lower-income households and are further from the central business district. Increasing the supply of affordable housing in closer proximity to jobs is another possible solution. By better supporting the more vulnerable neighborhoods, we are supporting improved resiliency and strength of the community as a whole. These solutions will strengthen these communities by offering adaptive and alternative transportation choices, supporting the economic, social, and environmental strength of cities and towns. 
Acknowledgments Thanks goes to my advisor for his guidance, support, and vision on this project. Thanks also to other faculty members and my peers in the ACT Research Group for their support. This study was made possible thanks to data from the City and County of Denver and the Denver Regional Council of Governments. Funding for this work was provided by the Mountain-Plains Consortium, Grant Number MPC-361, a program sponsored by the U.S. Department of Transportation.

\section{References}

ACS 2006 to 2010 (5-Year Estimates) (2013) Social explorer. Social Explorer Professional

Alam JB, Wadud Z, Polak JW, Alam JB (2013) Energy demand and economic consequences of transport policy. Int J Environ Sci Technol 10:1075-1082. doi:10.1007/s13762-013-0240-1

Battelle (2007) Evaluation of system's available redundancy to compensate for loss of transportation assets resulting from natural disaster or terrorist attacks. National Surface Transportation Policy and Revenue Study Commission, Washington

Ben-Akiva M, Morikawa T (2002) Comparing ridership attraction of rail and bus. Transp Policy 9(2):107-116. doi:10.1016/S0967070X(02)00009-4

Berdica K (2002) An introduction to road vulnerability: what has been done, is done and should be done. Transp Policy 9(2):117-127

Brenkert A, Malone E (2005) Modeling vulnerability and resilience to climate change: a case study of India and Indian States. Clim Change 72(1-2):57-102

Briguglio L, CordinaG et al (2005) Conceptualizing and measuring economic resilience. University of Malta

Bruneau M, Chang S et al (2003) A framework to quantitatively assess and enhance the seismic resilience of communities. Earthq Spectra 19(4):733-752

Chang S, Nojima N (2001) Measuring post-disaster transportation system performance: the 1995 Kobe earthquake in comparative perspective. Transp Res A 35(6):475-494

Consumer Expenditure Survey (2013) Bureau of labor statistics. Accessed July 24. http://www.bls.gov/cex/home.htm

Cova TJ, Conger S (2004) Transportation hazards. In: Kutz M (ed) Handbook of transportation engineering. McGraw Hill, Washington, pp 17.11-17.24

Dodson J, Sipe N (2006) Suburban shocks: assessing locational vulnerability to rising household fuel and mortgage interest costs. Griffith University, Brisbane

DRCOG_-Front Range Travel Counts (2013) Denver regional council of governments. http://www.drcog.org/index.cfm?page=FrontRange TravelCounts

Echeverry J, Ibanez A et al (2004) The economics of transmilenio, a mass transit for Bogota, Universidad de los Andes

Ewing R, Cervero R (2010) Travel and the built environment: a meta analysis. J Am Plan Assoc 76(3):265-294. doi:10.1080/ 01944361003766766

Fitzgerald G (2012) The social impacts of poor access to transport in rural New Zealand, vol 484. NZ Transport Agency, New Zealand

Foster H (1995) Disaster mitigation: the role of resilience. In: Etkin D (ed) Proceedings of a tri-lateral workshop on natural hazards. Merrickville, ON, Canada, pp 93-108

Freckleton D, Heaslip K, Louisell W, Collura J (2012) Evaluation of transportation network resiliency with consideration for disaster magnitude. Presented at the 91st annual meeting of the transportation research board, Washington, DC

Godschalk DR (2003) Urban hazard mitigation: creating resilient cities. Nat Hazards Rev 4(3):136-143. doi:10.1061/ ASCE!1527-6988
Haas PM, Makarewicz C, Benedict A, Bernstein S (2008) Estimating transportation costs by characteristics of neighborhood and household. Transp Res Rec J Transp Res Board 2077:62-70. doi: 10.3141/2077-09

Hanson S (2004) The geography of urban transportation, 3rd edn. The Guilford Press, New York

Harkey DL, Zegeer CV (2004) PEDSAFE: pedestrian safety guide and countermeasure selection system. University of North Carolina, Highway Safety Research Center, Chapel Hill

Heaslip, K, Louisell WC, Collura J (2009) A methodology to evaluate transportation resiliency for regional networks. Presented at the 88th annual meeting of the transportation research board, Washington, DC

Heaslip, K, Louisell WC, Collura J, Serulle NU (2010) A sketch level method for assessing transportation network resiliency to natural disasters and man-made events. Presented at the 89th annual meeting of the transportation research board, Washington, DC

Husdal J (2004) Why reliability and vulnerability should be an issue in road development projects. Samferdsel: Journal of the Norwegian Institute of Transport Economics (3)

Light-Duty Automotive Technology and Fuel Economy Trends: 1975 through 2007 (2007) EPA-420-R-07-008. Environmental Protection Agency Office of Transportation and Air Quality, Washington, DC

Lipman BJ (2006) A heavy load: the combined housing and transportation burdens of working families. Center for Housing Policy, Washington

Long JS (1997) Regression models for categorical and limited dependent variables (advanced quantitative techniques in the social sciences). Sage, Thousand Oaks

Martin WA, McGuckin NA (1998) Report 365: travel estimation techniques for urban planning. National cooperative highway research program. National Academy Press, Washington, DC

Mekuria M, Furth P, Nixon H (2012) Low-stress bicycling and network connectivity. Final report CA-MTI-12-1005. Mineta Transportation Institute, San Jose State University

Metro Denver, Colorado-Income Growth for Region (2013) Metro denver economic development corporation. Accessed November 12. http://www.metrodenver.org/demographics-communities/ demographics/income.html

Murray-Tuite PM (2006) A comparison of transportation network resilience under simulated system optimum and user equilibrium conditions

Newman P, Beatley T, Boyer H (2009) Resilient cities: responding to peak oil and climate change. Island Press, Washington

Nouri J, Malmasi S (2004) Environmental impact assessment of urban development plan by vulnerability model application. Int $\mathbf{J}$ Environ Sci Technol 1(1):7-15

Pelling M (2003) The vulnerability of cities: natural disasters and social resilience. Earthscan Publications, London

Rassafi AA, Vaziri M (2005) Sustainable transport indicators: definition and integration. Int J Environ Sci Technol 2(1):83-96

Scherer M (2010) Is light rail more attractive to users than bus transit: arguments based on cognition and rational choice. Transp Res Rec J Transp Res Board 2144:11-19. doi:10.3141/2144-02

Serulle NU, Heaslip K et al (2011) Resiliency of transportation network of Santo Domingo, Dominican Republic case study. Transportation Research Record 2234

Weekly U.S. All Grades All Formulations Retail Gasoline Prices (Dollars per Gallon) (2013) US energy information administration. July 23. http://www.eia.gov/dnav/pet/Hist/LeafHandler. ash $\mathrm{x}$ n=PET\&s=EMM_EPM0_PTE_NUS_DPG\& $\mathrm{f}=\mathrm{W}$

Zheng J, Garrick NW et al (2010) Quantifying the economic domain of transportation sustainability. Transportation Research Board, Washington, DC 